Environmental Research Journal 6(3): 235-238, 2012

ISSN: 1994-5396

(C) Medwell Journals, 2012

\title{
Flora of Ecological and Economic Interest of the Area Dreat (Northern of Hodna, Algeria)
}

\author{
${ }^{1}$ Bounar Rabah, ${ }^{2}$ Bahlouli Faycal, ${ }^{1}$ Rebbas Khellaf, ${ }^{1}$ Ghadbane Mouloud, \\ ${ }^{2}$ Cherief Abdelkader and ${ }^{1}$ Benderradji Laid \\ ${ }^{1}$ Department of Nature and Life Sciences, ${ }^{2}$ Department of Agronomy, \\ Faculty of Sciences, University of M'Sila, 28000 M'Sila, Algeria
}

\begin{abstract}
The area of Dreat extends on a surface from 16880 ha. It shelters 319 species belonging 208 botanical kinds and to 51 families. The families most represented are the family of Asteraceae followed by the family of Fabaceae, Brassicaceae, the family of Lamiaceae, the family of Poaceae and other family with small degree of presence. This zone is primarily made up by species of Mediterranean stock. The biological types most represented are: the therophytes and the hemicryptophytes followed by the geophytes, the phanerophytes and the chamaephytes are represented. This floristic diversity contains 28 endemic (s.1.), 32 rare species and 141 plants of economic interest.
\end{abstract}

Key words: Hodna, Dreat, flora, endemic, rare, plants of economic interest

\section{INTRODUCTION}

The Mediterranean forests represent a fragile natural environment and deeply disturbed by the action of the man. From the point of view of their conservation, dramatic problems arise dice a as well present at the level of the gasolines of which some are in natural situation near to the extinction as structures of vegetation. Emergency solutions will have to be found as soon as possible, to ensure their safeguard. Their conservation can be assured only so administrative and users clearly take conscience of their importance ecological and economic which is unfortunately not often case (Quezel and Barbero, 1990).

The biodiversity plays a significant role in the maintenance of the structure, the stability and the operation of the ecosystems and in particular of their productivity.

The conservation and the valorization of the diversity of the genetic resources of the plants of a country suppose initially the precise knowledge of this inheritance. On the basis of the complexity of a flora in perpetual evolution, the definition of an optimal strategy giving all the means to the operators constitutes the guarantee to achieve this goal (Chemli, 1997). The area of Dreat presents a rich and diversified flora. It is characterized by an endemic and rare flora.

The history of the aromatic and medicinal plants is associated the evolution of civilizations. In all the areas of the world, the history of the people shows that these plants always occupied a significant place in medicine in the composition of the perfumes and the culinary preparations. The valorization of these vegetable natural resources passes primarily by the extraction of their essential oils (HE). These last are products with strong added value, used in pharmaceutical, cosmetic industries and agroalimentary (Amarti et al., 2011). With an aim of developing this inheritance, researchers contributed to the floristic inventory of this area followed by an analysis of its flora of economic interest.

Presentation of the zone of study: The area of Dreat belongs to the commune of Hammam Dalaa (Fig. 1), it is localised in North East of place head of Wilaya of Me Sila. It is limited to North and is by Bordj Bou Arreridj (Douar Selatna and Mansoura) in the South by the commune of Tarmount and in the West by the commune of Ouanougha.

It is characterized by a very broken relief with altitudes which culminating with $1555 \mathrm{~m}$ and of the variable slopes, the morphometry of the zone of Hammam Dalaa emphasizes the mountainous zone in North with its very broken relief and its strong slopes. Is in the West follow one another the solid masses of Djebel chouckchout (1852 m), Djebel Djedoug (1244 m), Djebel Mansour (Dreat) and kef el Assel (1223 m).

The hydrological network in Hammam Dalaa is very dense. It belongs to under catchment area of oued

Corresponding Author: Bounar Rabah, Department Nature and Life Sciences, Faculty of Science, University of M'Sila, 28000 M'Sila, Algeria 


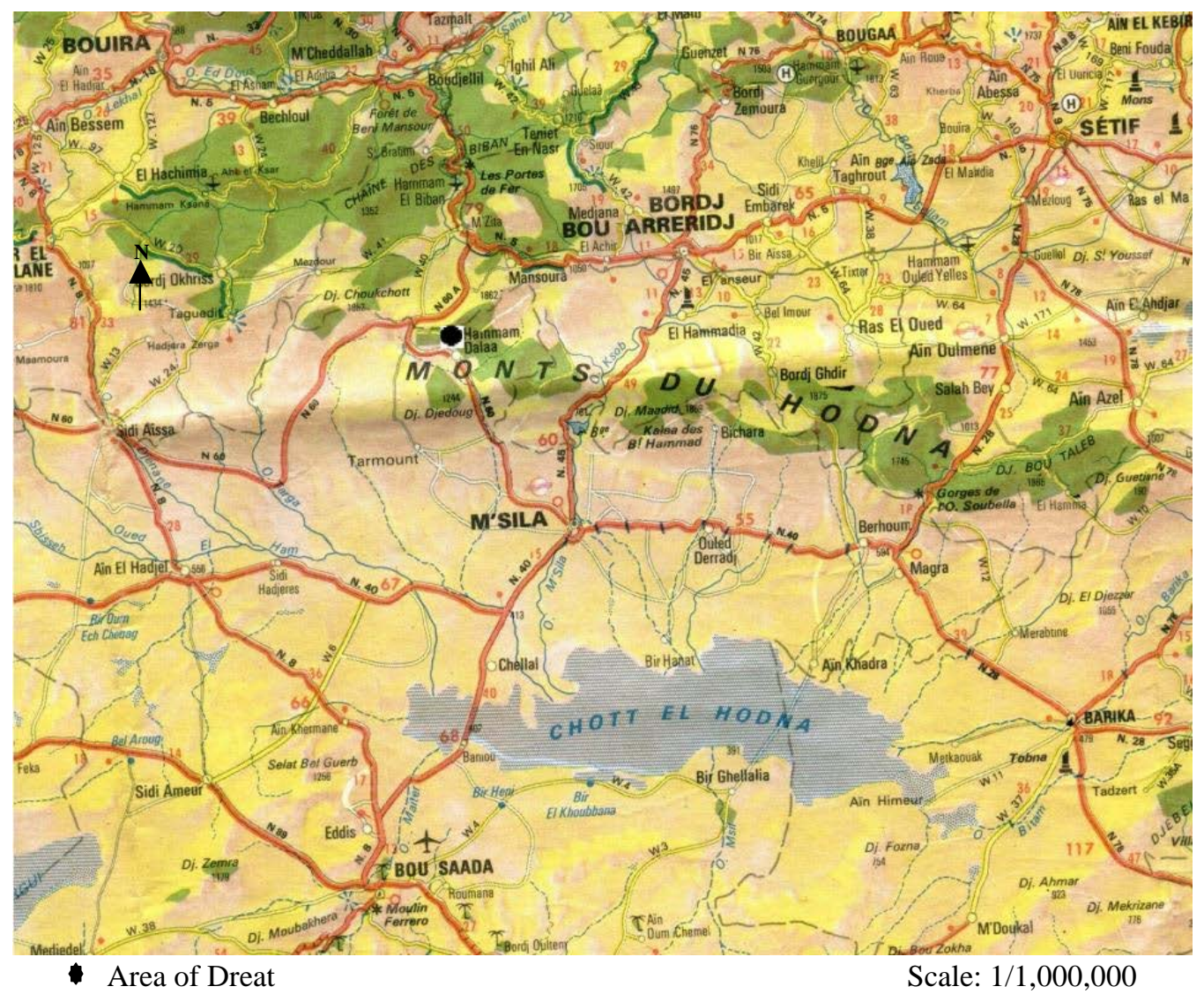

Fig. 1: Geographical localization of the zone of study (extract of tourist chart ONAT)

Loughmene, the principal oued are: Loughmene, El Hammam (Sidi Amer), El Haourane, El Gattar, Guetif, Annseur and Haramme. The area of Dreat is a mountainous zone composing primarily by limestones and marls.

One distinguishes the various types of classes of the ground following: rough mineral grounds, grounds not very advanced, grounds calcimagnesic, grounds halomorphic, grounds hydromorphic and grounds isohumic.

The averages of the annual precipitations recorded during the series (1988-2008) are: $212 \mathrm{~mm}$ at the station of M'Sila and $657 \mathrm{~mm}$ with $1555 \mathrm{~m}$ of altitude on the level of Dreat. July corresponds to the hottest month and January is the coldest month for the zone of study.

\section{MATERIALS AND METHODS}

The way simplest to define the biodiversity is to present it like the diversity of all the forms of the alive one. It is all the variety of alive studied on three levels.
The various aspects of the biodiversity are: genetic diversity, the diversity of the species and ecological diversity or diversity of the ecosystems.

The floristic inventory follows the following stages: exits on the ground, North-South and East-West transects; collect samples of plants and for the determination of the collected species, researchers used the New flora of Algeria of Quezel and Santa (1963), the flora of North Africa of Maire (1987) and Flora Corsica of Jeanmonod and Gamisans (2007). The analysis of the flora of Dreat enabled us to emphasize a significant list of plants of economic interest.

\section{RESULTS AND DISCUSSION}

The zone of study shelters 319 species belonging 208 kinds and 51 families. The family most represented is that of Asteraceae with 37 genres and 59 species.

The biological spectrum (Fig. 2) shows that Therophytes are more dominant with $48.41 \%$. The therophytes are supported by less thick cover. Their 


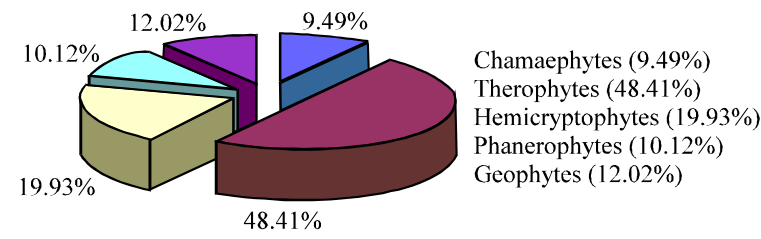

Fig. 2: Biological spectrum of Dreat

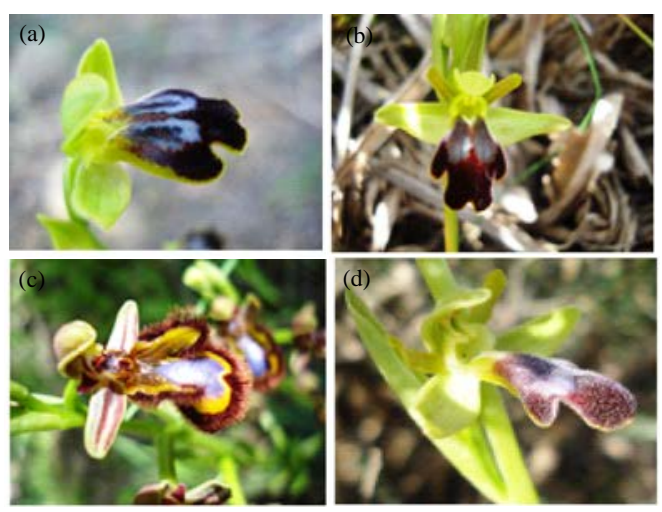

Fig. 3: a) Ophrys marmorata G. Foelsche and W. Foelsche, b) Ophrys fusca Link, c) Ophrys speculum Link, d) Ophrys mirabilis $\mathrm{P}$. Geniez and F. Melki (K. Rebbas, 2008 to 2010)

predominance is sign of aridity of the medium. The codominance of the therophytes shows the importance of the anthropic action and the overgrazing in this zone.

Geophytes of which we inventoried 6 orchises and the phanerophytes are less abundant and the chamaephytes has small percentage (9.49\%). Among these orchises (Fig. 3) one a: Ophrys speculum Link, Ophrys fusca Link, Orchis anthropophora L. Allioni, Ophrys tenthredinifera Willdenow and a new Ophrys for Algeria: Ophrys marmorata G. Foelsche and W. Foelsche which is endemic of Corsica and Sardinia of origin stenomediterraneen (Jeanmonod and Gamisans, 2007) and a second station of Ophrys mirabilis P. Geniez and F. Melki were discovered by one of us (R.K). The first station of Ophrys mirabilis $\mathrm{P}$. Geniez and F. Melki was discovered in Kabylie in 2008 (Rebbas et al., 2009; Rebbas, 2011; Rebbas and Vela, 2011). The zone of study is primarily made up by species of Mediterranean stocks (222 species)

This zone contains 28 endemic (s.1.) and 32 rare species like: Astragalus armatus ssp. tragacanthoides (Desf) Mayor, Hedysarum naudinianum L. (Coss), Centaurea involucrata Desf., Helianthemum helianthemoides (Desf) Grosser, Centaurea will parviflora Desf, Centaurea pungens Pomel, Pulicaria arabica ssp. inuloides (cd.) Mr., Erinacea pungens Boiss, Hydesarum spinosissimum ssp. eu spinosissimum Briq, Rupicapnos numidicus Pomel, maximum Androsace L., Rhamnus alaternus ssp. myrtifolia (Willd) Mr., Pituranthus scoparius Benth and Hook, Solenanthus lanatus cd., Helianthemum hirtum ssp. ruficomum (Viv) M., Trifolium melilotus-ornithopodioides L., Evacidium discolor (DC.) M. and Ebenus pinnata L. We counted 141 species of economic interest, 112 of medicinal species and 29 species of Fabaceae.

The development of research in the field of the pharmacology and the identification of the active ingredients of the species will allow the creation of an economic activity around the use of the plants within a respectful organized framework of the safeguard of the flora.

The anarchistic exploitation of the species known for their economic interest (medicinal and food) constitutes a risk for their survival.

Certain species are in danger of extinction because of their overexploitation (abusive pulling up). It is the case of the species of Lamiaceae which are systematically torn off with their roots to be resold in the cities and the villages of the area.

In this area, since the old generations, the traditional use of the medicinal plants still persists and that in spite of the revolution of medical technology. The multiplication of the floristic and ethnobotanic studies on a national scale will make it possible to better know the potentialities in this field.

Proposal of the alteration work: Each action of installation is conditioned by definite laws themselves by ecological and biological studies of all the elements of territory with households.

To develop the vegetable formations and to put an end to the process of degradation which touches the forest belts of this area, we brought some proposals for an installation: the construction of the basins buried in the ground makes it possible to minimize the propagation of the fires, to widen and cleanse the trenches fire wall to serve greatest possible surface in the event of fire. The stations of watchtowers of the zone of study require repairs and amenagement existing networks of the tracks. The whole of the zone of study requires plant health operations.

\section{CONCLUSION}

The area of Dreat presents a rich and diversified flora, containing 319 species belonging to 51 botanical families and 208 kinds which are listed on the level of various 
biotopes. The families most represented are the family of Asteraceae followed by: the family of Fabaceae, Brassicaceae, the family of Lamiaceae and the family of Poaceae and other families with small degree of presence. This floristic richness contains 28 endemic species, 32 rare species and 141 of species of economic interest.

This zone is primarily made up by species of Mediterranean stock. The biological types most represented are: therophytes and hemicryptophytes followed by the geophytes and the phanerophytes and the chamaephytes to small percentage. The biodiversity is an inheritance of humanity and must be preserved the whole of existing genetic diversity.

It is desirable to draw up a precise assessment of the biodiversity in the area. This assessment will make it possible to undertake socio-economic activities of local and regional interest.

\section{RECOMMENDATIONS}

Thus, the presence of the rare and endemic vegetable species would deserve a greater attention and to be the subject of specific studies. The specificity of habitat, the taxinomic originality and the temporal persistence of the species constitute also useful criteria in the definition of scarcity (Quezel and Medail, 2003). Some of let us tax rare and/or endemic profit from a protection in Algeria (executive Decree N 12-03 of 04 January 2012 fixing the list of the protected not cultivated vegetable species) like: Pulicaria arabica ssp. inuloides (CD.) M., Helianthemum helianthemoides (Desf) Grosser.

The implementation of a policy of conservation must imperatively take into account the socio-economic concerns of the local populations.

A significant number of spontaneous species of the zone of study have a potential value in comparison with medicine and food like fodder. The installation of processes of cultures of these species in the place of the anarchistic gathering can improve the income of the local populations while guaranteeing the conservation of floristic diversity. The culture of these plants of economic interest and their marketing will unquestionably increase the income of the populations.

This flora is of scientific interest fundamental for the knowledge and the knowledge in the field of ethnobotanic of the traditional pharmacopeia but also a scientific interest applied in the field of the valorization of the natural substances (Kaabeche, 2007).

\section{ACKNOWLEDGEMENTS}

Researchers make a point of warmly thanking the management staff for the forests of M'Sila and the district of the forests of Hammam Dalaa for their assistance lasting the exits on the ground.

\section{REFERENCES}

Amarti, F., M. El-Ajjouri, M. Ghanmi, B. Satrani and A. Aafi et al., 2011. Chemical composition, antimicrobic and antioxydant activity of the essential oil of Thymus zygis of Morocco. Phytotherapy, 9: $149-157$.

Chemli, R., 1997. Medicinal and aromatic plants of the flora of Tunisia. Ciheam: Medit. Options, 23: 119-125.

Jeanmonod, D. and J. Gamisans, 2007. Flora Corsica. Edisud, Aix-en-Provence, France, Pages: 921.

Kaabeche, M., 2007. Medicinal plants of Eastern Algeria: Taxonomy, ecology and farming possibility. Rev. Arid Areas, 2: 586-589.

Maire, R., 1987. Flora of North Africa: Morocco, Algeria, Tunisia, Tripolitaine, Cyrenaique and the Sahara. Vol. 16, Paul LeChevalier, Paris.

Quezel, P. and F. Medail, 2003. Ecology and Biogeography of the Forests of the Mediterranean Basin. Elsevier, Paris.

Quezel, P. and M. Barbero, 1990. Mediterranean forests, problems arising from their historical, ecological significance and their conservation. Acta Bot. Malacitana, 15: 145-178.

Quezel, P. and S. Santa, 1963. New flora of Algeria and of the Southernmost Steppe Areas. CNRS., Paris.

Rebbas, K. and E. Vela, 2011. Discovered of new stations of orchidee in Algeria on a transect Bibans/M'sila (Kabylie/Hodna). Proceedings of the International Symposium on Plant Species and Microbial Described in Algeria of 1962 to 2010. October 18-20, 2011, University USTO Oran, Algeria.

Rebbas, K., 2011. Orchidee of Algeria. University of M'Sila, Algeria.

Rebbas, K., M. Haddad and E. Vela, 2009. Contribution to the inventory of the orchidee of Kabylie (Algeria). Proceedings of the 15th Conference on the Orchidee, May 30-April 1, 2009, Orchidophilie, France. 